it is at present developed upon which the scientific study of psychiatry rests. This must cover the phenomenological, psychological, biological, and sociological aspects of the subject, and the student's involvement would seem best insured by seminar teaching rather than by formal lectures. The student becomes familiar with the methods of inquiry in these several subjects, has a considerable amount of established knowledge to acquire, but even in a three-year period with so much to cover such courses cannot be expected to be both comprehensive and developed in depth. It will always be the student's own responsibility to select from the great range of available subjects a topic which he can pursue in depth if he wishes to do so. To help him in this a tutor selected from among his senior clinical teachers may prove invaluable.

Three types of achievement involving different skills, promoted by different motivations and dependent upon different human qualities, are now demanded of the psychiatrist élite. $\mathrm{He}$ is at once expected to be a scholar, a scientist, and a clinician. In the end he will be found to be predominantly excellent in one of these, not in all three. The scholar tends to be inhibited by the burden of his own knowledge and rarely has the freedom of mind the creative scientist requires. As clinician the scholar all too often lacks those human qualities without which the arduous life of dedication to patients is unattractive. The clinical scientist, however, pursues scholarship only within the field of his own interest and narrows the range of his clinical vision to the problems which as a scientist he is driven to explore. Too often he becomes a prisoner to his own techniques. The clinician, however, in daily and continuous contact with the whole range of illness, deviation, and disability, is primarily motivated not towards scholarship or to scientific inquiry for its own sake but to treatment and the alleviation of suffering. There is the ever-present danger that disregarding the insights and understanding which scholarship can provide, and the sense of criticism and scepticism which a scientific frame of mind can give, the clinician will degenerate into a technician, and in our present era a mere empiricist, purveying the products which our advanced pharmaceutical industries continue to develop and provide. The best hope for the avoidance of these dangers lies, in my opinion, in the intelligent and inspired partnership of university departments of psychiatry with those whose business it is to treat patients as they actually present in our society.

\section{REFEREKCES}

1 May, A. R., in Proceedings of IV International Congress of World Federation of Occupational Therapists, 1967, edited by R. L. Kleinmann, p. 235. London. 2 Report of Royal Commission on Medical Education, 1965-1968, 1968.

3 Ministry of Health. National Health Service: The Administrative Structure of the Medical and Related Services in England and Wales, 1968. H.M.S.O., London.

- General Medical Council, Recommendations as to Basic Medical Education, 1967. London.

s Wilson, G. M., Brit. f. med. Educ., 1967, 1, 103.

- Platt, Lord, Brit. med. F., 1967, 4, 439.

\title{
Cardiac Monitoring in a Regional Hospital
}

\author{
CLIVE P. ABER,* M.D., B.SC., M.R.C.P. ; R. W. PORTAL,* M.D., M.R.C.P.; M. P. CHOPRA, $\dagger$ M.B., B.S.
}

Summary : The first 18 months' experience in a selfcontained, 9-bedded cardiac monitoring unit in a regional general hospital is reported. Of 667 admissions, $373(56 \%)$ had acute myocardial infarction. Of these, 61 (16\%) patients suffered cardiac arrest(s), and 11 were successfully resuscitated. The overall mortality was $13.4 \%$, which compares favourably with other series reported.

\section{Introduction}

Recent reports from teaching hospitals have shown a high incidence of benign and a lower incidence of potentially dangerous dysrhythmias after myocardial infarction (Fluck et al., 1967 ; Lawrie et al., 1967 ; Restieaux et al., 1967 ; Stock et al., 1967 ; Pentecost and Mayne, 1968). The prompt recognition and treatment of ventricular fibrillation and heart block have appreciably reduced the mortality from such dysrhythmias when they occur in patients cared for in specialized cardiac monitoring units, where there is rarely a problem in providing adequate numbers of trained medical and nursing staff. On the other hand, the value of cardiac monitoring in regional (nonteaching) hospitals is as yet undetermined, since no report from such a unit in this country has been published. We therefore

\footnotetext{
* Consultant Physician.
† Research Assistant.

Department of Cardiology, Kingston General Hospital, Hull.
}

report our first 18 months' experience in a nine-bedded monitoring unit in a regional hospital.

\section{Description of Unit}

The unit is a self-contained nine-bedded ward with mixed sexes on the ground floor of a general hospital in the centre of Hull. Each bed is equipped with an oscilloscope (Cardiorater, Cardiac Recorders, with rectangular screen 4 by 3 in.; 10 by $7.5 \mathrm{~cm}$.), piped oxygen (humidified), piped suction, and an aneroid sphygmomanometer (Accoson, 6-in. (15-cm.) face) fixed to the wall above the head of each bed. The beds are specially constructed with detachable head and foot boards. The head and foot of the beds can be raised or lowered through $20^{\circ}$. They stand at least $6 \frac{1}{2} \mathrm{ft}$. $(2 \mathrm{~m}$.) apart and are clearly visible from the nursing station at one end of the ward. A single-channel oscilloscope incorporated in the nursing-station desk permits the serial inspection of the nine electrocardiograms. An alarm switch to summon medical and nursing aid is placed at the head of each bed and also in the nursing station. When this is thrown, the duty registrar, house-officer, and three senior nurses are summoned by a Multitone call system. A D.C. defibrillator (Cardiac Recorders, Type 61A), a pacemaker (Cardiac Recorders, Type 64A), an oscilloscope, and an emergency drug trolley are kept in the unit.

The unit is under the joint supervision of two consultant physicians, who alternate in a complete daily ward round. 
Continuous medical cover is provided by three house-officers attached to the cardiac department, at least one of whom is in or near the unit at all times. One also sleeps in a cubicle adjoining the unit. A registrar and a research assistant complete the medical complement. The nursing staff is of both sexes and consists of a male charge nurse, a sister, three staff nurses, five State enrolled nurses, and four junior nurses (students, pupils, and auxiliaries). An approximate three-shift system is worked throughout the 24 hours.

The unit provides a continuous service for emergency admissions, entry being by direct request from general practitioners, by transfer from the casualty department or other wards, or following domiciliary visits by the consultant staff. Patients of any age are eligible for admission.

\section{Criteria of Infarction}

The diagnosis of acute myocardial infarction was based on a characteristic history along with the E.C.G. criteria of the World Health Organization (1959) and/or a rise of serum enzymes (aspartate aminotransferase and $\alpha$-hydroxybutyrate dehydrogenase).

\section{Clinical Grading}

The severity of the clinical status on admission to the unit was assessed according to the following criteria, as suggested by the Ministry of Health.

(1) Mild.-No evidence of cardiac failure or hypotension (hypotension defined as systolic blood pressure below $100 \mathrm{~mm}$. $\mathrm{Hg}$.)

(2) Failure without Hypotension.-Persistent basal crepitations in the absence of respiratory disease, or any two of the following: dyspnoea, tachycardia greater than 100 per minute, raised jugular venous pressure, oedema, and gallop rhythm.

(3) Hypotension without Failure.-(a) Systolic blood pressure below $100 \mathrm{~mm}$. $\mathrm{Hg}$, with no other unfavourable features. (b) Systolic blood pressure below $100 \mathrm{~mm}$. $\mathrm{Hg}$, with more than one of the following: confusion, restlessness, pallor, cyanosis, sweating, and cold skin.

(4) Hypotension with Failure.-Systolic blood pressure below $100 \mathrm{~mm}$. $\mathrm{Hg}$, together with persistent basal crepitations in the absence of respiratory disease or any two of the following: dyspnoea, tachycardia greater than 100 per minute, raised jugular venous pressure, oedema, and gallop rhythm.

In 147 patients the Peel prognostic index (Peel et al., 1962) was also calculated.

\section{Routine}

Patients admitted to the unit routinely received continuous humidified oxygen by Franklin's nasal catheter at a rate of 4 litres a minute for 48 hours. An intravenous infusion of $5 \%$ dextrose solution ( $500 \mathrm{ml} . / 24$ hours) was given for the same period; this also served as an immediate channel for the administration of drugs in an emergency. Patients with proved or threatened myocardial infarction were treated with intravenous heparin (40,000 units $/ 24$ hours for two days) and phenindione. These drugs were withheld when the diagnosis of ischaemic heart disease was in doubt, and when otherwise contraindicated. Apart from anticoagulants no drug was given routinely. Digoxin or ouabain and diuretics were administered when there were clinical signs of heart failure or radiological evidence of pulmonary oedema. Heroin is now given for the relief of pain in preference to morphine or pethidine, both of which may produce a fall in blood pressure (Thomas et al., 1965 ; MacDonald et al., 1967 ; Rees et al., 1967).

Routine investigations during the patients' stay in the unit included conventional 12-lead electrocardiograms and serum enzyme estimations (aspartate and alanine aminotransferase and $\alpha$-hydroxybutyrate dehydrogenase) for the first three days. A portable chest $x$-ray film, haemoglobin, white cell count, sedi- mentation rate, blood urea, and serum electrolytes were obtained within the first 24 hours. Arterial blood gas analyses were performed (using an Instrumentation Laboratory $\mathrm{pH}$ blood analyser, model 113-S1) in patients with cardiac failure or persistent dysrhythmias and following resuscitation from cardiac arrest.

The duration of the patients' stay in the unit was intended to be three days in uncomplicated cases. In practice this has been prolonged to an average of five days owing to a shortage of beds for "convalescent" patients in the medical wards. Despite this, on only four occasions has it been impossible to satisfy a request for admission to the unit. On leaving the unit the patients remain under the care of one or other of the two supervising physicians for the rest of their time in hospital.

\section{Management of Dysrhythmias}

Dysrhythmias were grouped in the manner described by Fluck et al. (1967) and treated along similar lines.

Supraventricular Tachycardias (atrial fibrillation and flutter, paroxysmal tachycardia).- If there was no undue clinical concern these dysrhythmias were treated initially with intravenous ouabain or oral digoxin. If cardiac failure or shock rapidly developed elective D.C. countershock was used, after an intravenous injection of heroin $(10 \mathrm{mg}$.) ; general anaesthesia was usually avoided. This procedure was necessary in five patients.

Atrial Transport Dysfunction.-Patients with nodal rhythm (with or without $\mathrm{A}-\mathrm{V}$ dissociation) were given an intravenous injection of atropine ( 0.6 to $1.2 \mathrm{mg}$.). If sinus rhythm returned within five minutes the drug was continued in a dosage of $0.6 \mathrm{mg}$. six-hourly for 24 hours.

Supraventricular Bradycardia.-Patients with a sinus bradycardia (heart rate less than $60 /$ minute) were treated similarly with atropine. If the heart rate increased significantly (10 or more beats/minute) atropine was continued for 24 hours.

Ventricular Tachycardia.-All patients with ventricular tachycardia or fibrillation received an immediate D.C. countershock, administered by medical or senior nursing staff.

Ventricular Bradycardia.-First- and second-degree heart block and Wenckebach's phenomenon were treated with intravenous atropine. Complete heart block without Adams-Stokes attacks was managed initially with atropine and corticosteroids. For the first 14 months the introduction of a transvenous pacing catheter was carried out blindly under E.C.G. control and reserved for patients in complete heart block with AdamsStokes attacks or cardiac failure, since no image intensifier was readily available in the unit. During the last four months the catheter has been placed with the aid of an image intensifier situated in the $x$-ray department 50 yards (46 metres) from the unit.

No specific therapy was given to patients with right or left bundle-branch block.

Multiple Ectopic Beats.-No uniform treatment was given for multiple ectopic beats during the first year. For the last six months intravenous lignocaine was administered according to the method of Lown et al. (1967) for any form of ectopic beat (atrial, nodal, or ventricular) that met one or more of the following criteria: (1) the occurrence of ectopic beats at a rate of more than $5 /$ minute ; (2) the occurrence of ectopic beats during the "vulnerable period" of the preceding beat; $(3)$ the occurrence of two or more consecutive ectopic beats; and (4) multiform configuration of ectopic beats. Results of this study are reported elsewhere (Chopra et al., 1969).

\section{Results}

In the 18 months since the opening of the unit (October 1966) 667 patients were admitted, of whom 373 (56\%) were 
shown to have had acute myocardial infarctions. The duration of acute symptoms before admission in the patients with infarcts is shown in Table I. A diagnosis of ischaemic heart disease was made in a further 149 patients, most of whom were admitted after an attack of ischaemic cardiac pain. A miscellany of diagnoses accounted for the remaining 145 patients; many were admitted after episodes of chest pain, acute dyspnoea, syncope, or "collapse," and a few for observation of various dysrhythmias.

TABLE I.-Duration of Recent Symptoms in 370* Patients with Acute Myocardial Infarction Before Admission to the Unit

\begin{tabular}{cccc|c|c}
\hline \multicolumn{2}{c|}{ Duration of Symptoms } & No. of Patients & Percentage \\
\hline $0-12$ hours & $\ldots$ & $\ldots$ & $\ldots$ & 218 & 59 \\
$13-24$ hours & $\cdots$ & $\cdots$ & $\cdots$ & 95 & 26 \\
$25-48$ hours & $\cdots$ & $\cdots$ & $\cdots$ & 45 & 12 \\
$>48$ hours & $\cdots$ & $\cdots$ & $\cdots$ & 12 & 3 \\
\hline
\end{tabular}

* Accurate information is not available on three patients.

\section{Dysrhythmias}

The frequency of persistent dysrhythmias is shown in Table II. These values must represent the minimal incidence of dyshythmias after myocardial infarction, since the present method of recording allowed only limited sampling. Left bundle-branch block was observed in 10 patients and right bundle-branch block in 9 . TABLE II.-Incidence of Dysrhythmias in 373 Patients with Acute

\begin{tabular}{|c|c|c|}
\hline Rhythm & No. of Patients & Percentage \\
\hline $\begin{array}{l}\text { Atrial fibrillation } \\
\text { Atrial flutter } \\
\text { Paroxysmal tachycardia }\end{array} \begin{array}{llll}\text { (atrial or nodai) } \\
\text { Nodal rhythm (with or without }\end{array}$ & $\begin{array}{r}26 \\
4 \\
15\end{array}$ & $\begin{array}{l}7 \cdot 0 \\
1 \cdot 1 \\
4 \cdot 0\end{array}$ \\
\hline 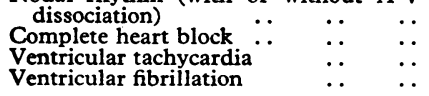 & $\begin{array}{r}23 \\
24 \\
1 \\
23\end{array}$ & $\begin{array}{l}6 \cdot 2 \\
6 \cdot 5 \\
0 \cdot 2 \\
6 \cdot 2\end{array}$ \\
\hline
\end{tabular}

\section{Cardiac Arrest}

Cardiac arrest occurred on one or more occasions in 61 $(16 \%)$ of the 373 patients with proved myocardial infarction. Resuscitation was attempted in 56 of these, of whom 11 ultimately left hospital. Resuscitation was not attempted in five patients-two in intractable congestive failure, one with leukaemia, one with haemolytic anaemia and renal failure, and one stuporous after a cerebrovascular accident. Forty patients were in the unit at the time of their arrest, and 10 of them survived. Only 1 out of 12 patients survived after resuscitation attempts in the wards (see Chart). In four patients the arrest

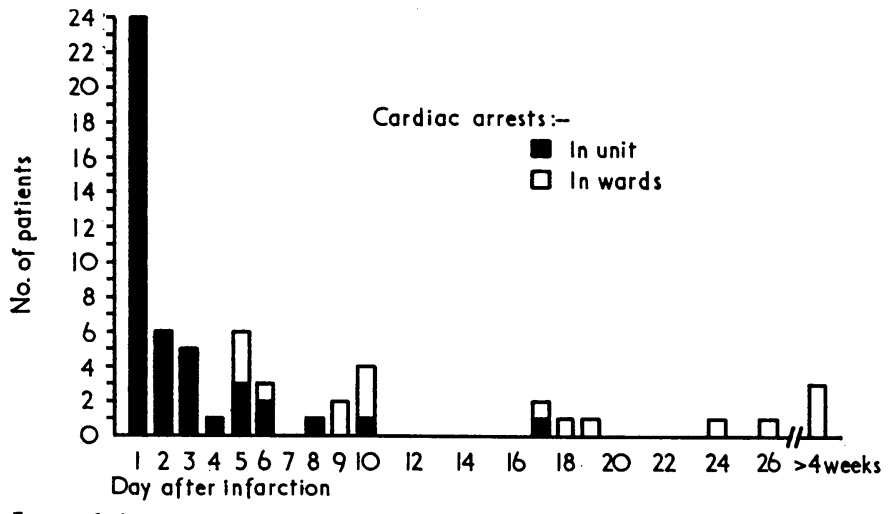

Interval between acute myocardial infarction and cardiac arrest in 61 patients. had occurred before they reached the unit, and they were moribund on arrival.

Ventricular fibrillation occurred on one or more occasions in 23 patients, with successful resuscitation and survival in 8 $(35 \%)$. Asystole (or heart block with extreme bradycardia) occurred in 33 patients ; 3 (9\%) of them ultimately left hospital after successful resuscitation. In five patients the terminal rhythm was not known.

Tables III and IV show the clinical grading on admission to the unit (M.O.H. criteria) and the Peel prognostic index (Peel et al., 1962) of the 57 patients who developed cardiac arrest and of the last 147 patients in the series.

TABLE III.-Clinical Grading of Severity (M.O.H.) and Prognostic Index (Peel et al., 1962) of 57 Patients Who Developed Cardiac Arrest After Acute Myocardial Infarction

\begin{tabular}{l|c|c|c|c|c|c|c|c|c}
\hline & \multicolumn{3}{|c|}{ Clinical Grading (M.O.H.) } & \multicolumn{3}{c}{ Peel Index } \\
\cline { 2 - 7 } & 1 & 2 & $3 a$ & $3 b$ & 4 & $1-8$ & $9-12$ & $13-16$ & $17+$ \\
\hline No. of cases .. & 30 & 16 & 1 & 4 & 6 & 17 & 11 & 15 & 14 \\
Deaths $\left\{\begin{array}{l}\text { No. } \\
\% . .\end{array}\right.$ & 20 & 16 & 1 & 3 & 6 & 11 & 9 & 12 & 14 \\
& & 100 & 100 & $75 \cdot 0$ & 100 & $65 \cdot 0$ & $82 \cdot 0$ & $80 \cdot 0$ & 100 \\
\hline
\end{tabular}

TABLE IV.-Clinical Grading of Severity (M.O.H.) and Prognostic Index (Peel et al., 1962) of 147 Patients with Acute Myocardial Infarction

\begin{tabular}{|c|c|c|c|c|c|c|c|c|c|}
\hline & \multicolumn{5}{|c|}{ Clinical Grading (M.O.H.) } & \multicolumn{4}{|c|}{ Peel Index } \\
\hline & 1 & 2 & $3 a$ & $3 b$ & 4 & $1-8$ & $9-12$ & $13-16$ & $17+$ \\
\hline $\begin{array}{l}\text { No. of cases .. } \\
\text { Deaths }\left\{\begin{array}{l}\text { No. } \\
\%\end{array} .\right.\end{array}$ & $\begin{array}{c}104 \\
10 \\
9 \cdot 6\end{array}$ & $\begin{array}{l}39 \\
8 \\
20 \cdot 4\end{array}$ & $\begin{array}{l}0 \\
0 \\
0\end{array}$ & $\begin{array}{l}\mathbf{0} \\
0 \\
0\end{array}$ & $\begin{array}{c}4 \\
3 \\
75 \cdot 0\end{array}$ & $\begin{array}{l}88 \\
6 \\
6 \cdot 8\end{array}$ & $\begin{array}{c}37 \\
4 \\
10 \cdot 8\end{array}$ & $\begin{array}{l}14 \\
5 \\
35 \cdot 7\end{array}$ & $\begin{array}{l}8 \\
6 \\
75 \cdot 0\end{array}$ \\
\hline
\end{tabular}

Of the $373^{\prime}$ patients with acute infarcts $50(13.4 \%)$ died in hospital. These include the four patients whose arrest occurred before arrival in the unit. There was no cardiac arrest among the 149 patients with ischaemic heart disease but no proved infarct. The relation between age and mortality is shown in Table V.

TABle V.-Age and Mortality of 373 Patients with Acute Myocardial Infarction

\begin{tabular}{|c|c|c|c|}
\hline Age & No. of Patients & No. of Deaths & $\%$ of Deaths \\
\hline $\begin{array}{l}30-39 \\
40-49 \\
50-59 \\
60-69 \\
70-79 \\
80-89\end{array}$ & $\begin{array}{r}9 \\
60 \\
142 \\
145 \\
15 \\
2\end{array}$ & $\begin{array}{r}0 \\
3 \\
19 \\
24 \\
3 \\
1\end{array}$ & $\begin{array}{c}0 \\
5.0 \\
13.4 \\
16.5 \\
20.0 \\
50.0\end{array}$ \\
\hline Total & 373 & 50 & $13 \cdot 4$ \\
\hline
\end{tabular}

\section{Discussion}

The various modes of entry into the unit inevitably resulted in the admission of patients with unexplained chest pain, syncope, and varieties of "collapse," many of whom were not suffering from ischaemic heart disease. In this respect a ninebedded unit permits more latitude than would a smaller one, and serves to some extent as a "sorting-ground." Though this may at first appear to be a misuse of the facilities, we have found it no disadvantage, for the intensive study available in the unit results in a more rapid assessment than would take place in a general ward and an earlier discharge of patients whose condition does not justify retention in hospital.

The accommodation of convalescent patients has not been as great a problem as was anticipated, since nearly half those admitted had not had infarcts and therefore an earlier discharge was possible. Though the intended three-day stay in the unit was not adhered to, the average stay of the uncomplicated patient was only five days. 
The mixing of the sexes in the unit has not given rise to difficulties and is accepted by the patients in most cases without comment. This may be explained partly by the age of the patients, the fact that they are confined to bed, and the wide spacing of the beds with their adequate curtain soreening.

We have been reluctant to abandon the principle of continuity of medical supervision during the remainder of the patient's stay in hospital. In ischaemic heart disease differences in emphasis on various aspects of management (duration of bed rest, diet, anticoagulants, subsequent activity) are only too prone to occur, with the result that the patient is frequently confused by conflicting advice. Our practice here is at variance, however, with that described at other centres (Lawrie et al., 1967).

The method of monitoring used, without a continuous E.C.G. record or regular sampling, does not reveal the true incidence of dysrhythmias in the post-infarction period. The incidence noted is similar to that found in other units (Jewitt et al., 1967 ; Lawrie et al., 1967 ; Pentecost and Mayne, 1968), and our experience in this matter requires no further elaboration.

Though accurate information is not available a strong impression exists that during the day the nursing staff's attention was far more often drawn to a patient in cardiac arrest either by a change in his posture or behaviour or by a signal from an adjacent patient than by the oscilloscope or alarm signal. On the other hand, at night such incidents have of ten been first observed on the monitors. The presence of both male and female nurses may well be advantageous in such units, which use a variety of electronic apparatus. The higher success rate of resuscitation in the unit (10 out of 40 patients) than in the wards ( 1 out of 12 patients) cannot be attributed to differences in the extent of myocardial damage, but probably reflects the readier availability of resuscitation apparatus in a relatively small ward where highly trained nursing staff are alert to the risk of cardiac arrest in all patients under their care.

The overall mortality of $13.4 \%$ in this series compares favourably with that reported by others (Table VI). Since there was no intentional selection of patients with infarction in this series, and $59 \%$ of them were admitted within 12 hours of the onset of symptoms, it is unlikely that a significant further reduction in mortality will be achieved. The 11 patients who were successfully resuscitated after cardiac arrest and left hospital constitute the one figure on which the justification of such units rests. As yet there is no way of knowing whether the other patients would have fared differently in general medical wards or at home. However, it is important to realize that about $50 \%$ of the patients who developed cardiac arrest were assessed clinically as either grade I severity (M.O.H.) or had a Peel index of less than 13 on admission to the unit. Such patients, whose resuscitation success rate was high (30\%), might have been kept at home had their domestic circumstances been favourable.

TABLE VI.-Mortality of Patients Admitted to Monitoring Units

\begin{tabular}{|c|c|c|}
\hline Hospital and Author & $\begin{array}{c}\text { Total No. } \\
\text { of Patients with } \\
\text { Myocardial Infarction }\end{array}$ & $\begin{array}{c}\text { Mortality } \\
(\%)\end{array}$ \\
\hline 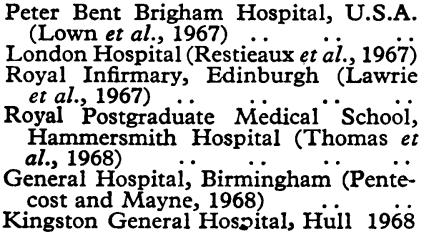 & $\begin{array}{l}130 \\
150 \\
400 \\
150 \\
232 \\
373\end{array}$ & $\begin{array}{l}19.0 \\
18.5 \\
13.4\end{array}$ \\
\hline
\end{tabular}

It is of interest that no cardiac arrest occurred in the 149 patients admitted with ischaemic pain but without a proved infarct. This supports the view that a dangerous dysrhythmia is unlikely to develop in the absence of an area of myocardial necrosis large enough to cause conventional E.C.G. changes or a rise in serum enzymes.

We wish to pay tribute to the late Dr. A. R. Cumming, through whose initiative this unit was founded.

\section{REFERENCES} Chopra, M. P., Portal, R. W., and Aber, C. P. (1969). Brit. med. F.,

Fluck, D. C., et al. (1967). Brit. Heart f., 29, 170.

Jewitt, D. E., Balcon, R., Raftery, E. B., and Oram, S. (1967). Lancet, 2, 734 .

Lawrie, D. M., et al. (1967). Lancet, 2, 109.

Lown, B., Fakhro, A. M., Hood, W. B., and Thorn, G. W. (1967). f. Amer. med. Ass., 199, 188.'

MacDonald, H. R., Rees, H. A., Muir, A. L., Lawrie, D. M., Burton, J. L., and Donald, K. W. (1967). Lancet, 1, 1070.

Peel, A. A. F., Semple, T., Wang, I., Lancaster, W. M., and Dall, J. L. G. (1962). Brit. Heart f., 24, 745.

Pentecost, B. L., and Mayne, N. M. C. (1968). Brit. med. f., 1, 830.

Rees, H. A., Muir, A. L., Macdonald, H. R., Lawrie, D. M., Burton, J. L., and Donald, K.' W. (1967). Lancet, 2, 863.

Restieaux, N., et al. (1967). Lancet, 1, 1285.

Stock, E., Goble, A., and Sloman, G. (1967). Brit. med. F., 2, 719.

Thomas, M., Malmcrona, R., Fillmore, S., and Shillingford, J. (1965). Brit. Heart f., 27, 863 . Thomas, M., Jewitt, D. E., and Shillingford, J. P. (1968). Brit. med. F.,
1, 787. World Health Organization (1959). Wld Hlth Org. techn. Rep. Ser., No. 